\title{
El mal de la pereza y sus repercusiones ideológicas en el Poema de Alfonso Onceno
}

\section{The Flaw of Lazyness and its Ideological Repercussions in the Poema de Alfonso Onceno}

\author{
ERICA JANIN \\ Conicet-UBA-Secrit-IFLH \\ bonifacio_vino@yahoo.com.ar
}

\begin{abstract}
RESUMEN
Este estudio busca demostrar que la caracterización del enemigo musulmán como perezoso que se hace en el Poema de Alfonso Onceno no debe entenderse como parte de un procedimiento descriptivo neutral, sino como una herramienta política e ideológica que busca delimitar el campo de los enemigos y de los aliados, incluso en el interior del bando cristiano, para justificar una serie de acciones de promoción o detracción que se lleva adelante sobre cada uno de los grupos que conviven en el poema.
\end{abstract}

Palabras Clave: Poema de Alfonso Onceno, pereza, esfuerzo, enemigo, legitimación

\begin{abstract}
This study seeks to prove that the characterisation of the Muslim foe's laziness portrayed in the Poema de Alfonso Onceno's should not be conceived as a part of a neutral descriptive procedure. On the contrary, it should be understood as a political and ideological tool that seeks to delimit the field of foes and allys — even within the christian faction -, in order to justify a series of actions of promotion or reprobation towards each of the social groups that coexist in the poem.
\end{abstract}

KeYwords: Poema de Alfonso Onceno, laziness, effort, foe, legitimization

FECHA DE RECEPCIÓN: 25/10/2019

FECHA DE ACEPTACIÓN: 29/01/2020

L as comunidades apuestan a conseguir su cohesión social mediante diversos mecanismos, entre los que podemos contar determinados valores compartidos, la ejecución de un cuerpo de normas que atañen al 
colectivo, una historia (un relato) que identifica a sus miembros, una religión que los une, costumbres y tradiciones compartidas, una lengua, etc. Estos mecanismos pueden actuar en conjunto o puede bastar la puesta en marcha de algunos para alcanzar cierta unidad. Ahora bien, así como fácilmente podemos enumerar una cantidad de aspectos dadores de identidad que podríamos caracterizar como obvios (leyes, costumbres, una lengua), hay otros aspectos que obran en el mismo sentido que no son tan evidentes. Un caso es el miedo, otro caso, el odio. El miedo y el odio al otro son elementos que pueden resultar fundamentales en el proceso de construcción de una identidad. Pero ¿cómo se plasma el miedo, la repulsión o, simplemente, la reprensión al ajeno? La lista de tachas atribuibles al extranjero, al integrante de otra clase social, al enemigo político, al devoto de otro Dios, ¿debe ser muy larga o basta con la atribución de unas pocas taras o vicios para iniciar el camino de la descalificación?

La literatura medieval y, más que otras manifestaciones, la literatura épica, muestra un abanico de males imputables a personajes que asumen el rol del otro. En la Chanson de Roland el mal parece irredimible y sus actores inintegrables al campo del nosotros. Ganelón, el enemigo interno, es un traidor que se hace acreedor de una serie de insultos vinculados al campo semántico de la felonía, cuyo mal se conjura con su muerte. Mientras que los enemigos musulmanes son animalizados y satanizados continuamente: viven en un lugar maldito, donde el sol no brilla y la lluvia no cae, donde el trigo no crece y todo es negro, un lugar donde viven/ mean los diablos, que, podemos suponer, ha de ubicarse en las antípodas espirituales de la dulce Francia. Son negros como la pez derretida, pérfidos, asesinos, no juegan ni ríen, relinchan y ladran. ${ }^{1}$

En el Cantar de Mio Cid la evaluación de buenos y malos es menos polar y más polifacética. El enemigo interno, representado por los infantes de Carrión, es alguien digno de desprecio y burla, cuyo castigo consistirá en ser exiliado de la vida de corte mediante una acusación de menos valer. La visión del enemigo externo no tiene nada que ver con la de la Chanson, pues parece haber más conciencia de que el enfrentamiento es por el dominio del territorio y la adquisición del botín, al margen de que las religiones oficien de telón de fondo del conflicto.

Pero en cualquiera de los ejemplos es claro que el procedimiento de construcción del nosotros implica un correlato, en estos casos explícito, que

\footnotetext{
${ }^{1}$ Como ejemplo pueden leerse las tiradas 78, 125 y 256 de la Chanson según la traducción de Isabel de Riquer.
} 
involucra la destrucción del otro. Y esto a causa del proceso de territorialización narrado en los cantares, que supone la ocupación, la delimitación y la posterior defensa del territorio con el que se identifica y crea lazos la comunidad.

En el Poema de Alfonso Onceno, ${ }^{2}$ como en casi todas las obras épicas, contamos con dos grandes enemigos que encarnan dos manifestaciones del mal. ${ }^{3}$ Hay un "otro" (entre comillas) o mal menor que debe enfrentar el rey, que es un enemigo interno. Ese enemigo interno padece y/o genera varios males: mezquindad, avaricia, desconsideración, afán excesivo de poder, desobediencia, pero el peor de los males que produce es el desorden, pues el caos que instaura con su conducta desviada impide que el rey y sus vasallos leales puedan enfrentar con eficacia al verdadero enemigo de la cristiandad, en tanto deben destinar parte de sus esfuerzos a controlar a un grupo de díscolos nobles cristianos.

En relación con el segundo agente portador de mal, el enemigo externo, el Otro con mayúscula, podemos decir que acumula también una serie de males que en conjunto constituyen el Mal. Hubo varios intentos de explicar esa imagen particular que se pretende transmitir de los musulmanes en el $P A O$; aunque me detendré brevemente en los aportes de dos investigadores que tratan el tema de manera específica.

Cela Heffel destaca que la imagen del moro fuera del campo bélico responde al estereotipo del enemigo de la fe a riesgo incluso de olvidar el carácter monoteísta de ese enemigo; pero en el campo de las armas, cuando se habla de Albohacén se lo describe como un rey diestro en el arte de la guerra y como el único que podía aspirar a ser comparado en grandeza con Alfonso XI ("La función”, 6). Rodríguez Picavea, por su parte, concluye que el PAO transmite dos imágenes de los musulmanes, una individual y otra colectiva. La imagen individual no es unívoca. Cuantitativamente hay una predominancia de la imagen positiva, pues la mayoría de los musulmanes a los que se describe individualmente se presenta de ese modo, frente a cuatro personajes con características ambivalentes y dos que son descriptos de manera negativa; pero entre estos seis se hallan los dos personajes poéticamente más

\footnotetext{
${ }^{2}$ Serán utilizados en este trabajo como alternativas de Poema de Alfonso Onceno la forma breve Poema o la sigla PAO.

${ }^{3}$ Acerca de la discusión en cuanto a la clasificación genérica del Poema de Alfonso Onceno pueden verse las opiniones de Catalán, Poema; Catalán, Gran Crónica (especialmente 170 a 173); Vaquero, El "Poema"; Vaquero, “Contexto”; Fernández Gallardo, "Guerra santa”, 45-46; Nussbaum, Claves, 86-149; Gómez Redondo, Historia ("Poesía épica”, 123-158 y "Poemas noticieros e historiográficos: siglos XIII- XIV”, 185-207). En Janin, “Una vez más”, queda demostrado que el Poema pertenece al género épico.
}

Medievalia 52:1, 2020, pp. 41-58 
relevantes: Albohacén y Yusuf (“La visión”, 393). Albohacén algunas veces es presentado como un rey bravo y virtuoso, pero otras se lo describe como deshonrado, insensato, cobarde, ruin, comparado en ocasiones con el dragón, el puercoespín, el jabalí y el zorro, animales de carga negativa. ${ }^{4}$ En cuanto a Yusuf I su imagen es completamente negativa y nunca recibe elogios.

Incluso en aquellos casos de musulmanes que individualmente obtienen algún tipo de alabanza, se trata "de un recurso empleado por el autor para subrayar el mayor mérito de las victorias obtenidas por Alfonso XI frente a un adversario que también tenía sus virtudes" ("La visión", 393), porque la imagen como colectivo es negativa ("La visión”, 392). Justamente por la ambivalencia en la descripción a la que se ve obligado el poeta, en aras de exaltar a Alfonso enfrentándolo a un enemigo digno, por un lado, pero al mismo tiempo por la necesidad de volver al otro un ser exterminable, se hace necesaria la aclaración de las razones o los males por los cuales son dignos de repudio. Y entre esos procedimientos, el que salta rápidamente a la vista por ser un viejo conocido de los cantares épicos europeos, como señalan Cela Heffel y Rodríguez Picavea, y como ha sido indicado en el párrafo anterior, es la animalización. ${ }^{5}$

Como puede verse de la reseña breve de estos estudios, los vicios o las fallas del otro musulmán son muchos. ${ }^{6}$ No obstante, en esta ocasión me in-

${ }^{4}$ Como ejemplo pueden verse, en la edición de Ten Cate, las estrofas $1246,1351,1571$ y 1839.

${ }^{5}$ La operatividad de la animalización es explicada por Nogales Rincón en estos términos: "La animalización del contrincante político no sólo tenía un mero fin de desprestigio. La propia etiqueta de 'bestial', que tenía implicaciones de carácter religioso, buscaba, de una forma más o menos explícita, al negar la condición humana de la/s persona/s a quien/es se aplicaba, legitimar el dominio sobre ésta/s y, en casos extremos, la eliminación física del contrincante político exterior — principalmente el Islam - o interior” (“Animalización”, 289). Y centrándose específicamente en el caso del PAO dirá: "Significativo es, por su expresividad, un fragmento que el autor del Poema de Alfonso Onceno pone en boca del rey de Castilla. En dicho pasaje los súbditos del rey de Marruecos, figurado como un jabalí, son comparados con osos y cerdos, que habrán de ser cazados en una montería a manos del rey de Portugal" (Nogales Rincón, “Animalización”, 289). En un estudio llevado adelante sobre un corpus más amplio que el estudiado en este trabajo, Corbalán Vélez expone cómo la literatura de la época, a través de la estereotipación y desacreditación, colabora en la justificación de la expulsión o aniquilación de los musulmanes ("Aproximación", 3).

${ }^{6}$ Cabe señalar que la recurrencia a este tipo de procedimientos no es propio o exclusivo de la literatura producida en el período en la Europa cristiana. Y en ese sentido es interesante acercarse a la construcción del perfil de Alfonso XI en las producciones escritas de los musulmanes, donde se insiste en equipararlo a la figura del tirano y en atribuir sus éxitos a su buena suerte. Para estas cuestiones puede consultarse García Sanjuán, "Alfonso XI”.

Medievalia 52:1, 2020, pp. 41-58 
teresa reparar en un mal particular que se le atribuye y que coadyuva en el diseño de la figura de los castellanos por contraposición. Por lo que será mi objetivo centrarme en uno de los tantos "males" que caracterizan a los musulmanes y que, a pesar de ser menos evidente, y probablemente menos potente en una lectura superficial, que la animalización o la lista de pecados esperable en estos casos para diseñar la figura del enemigo, le permite al poeta construir, por antítesis, el perfil heroico de los cristianos y resaltar el mérito de los castellanos como un actor tan fundamental en la victoria como la ayuda divina. Me refiero al vicio de la pereza adjudicado a los infieles, que contrasta negativamente con la virtud del esfuerzo practicada por los castellanos leales a Alfonso.

Entenderé en este trabajo el término pereza como un ejercicio negativo del ocio, y no como equivalente exacto de acidia que, a pesar de ser un término algo ambiguo, entra en el grupo de los pecados capitales, de modo que su ejercicio entraña una gravedad mayor, pues en tal caso se trataría de un cuadro similar al que actualmente llamamos depresión, que involucra un tipo de pereza específica y grave desde una óptica cristiana y medieval, dado que implica la falta de ganas de vivir, rechazar la vida como don otorgado por Dios al ser humano. ${ }^{7}$

En este caso, por el contrario, se trataría de cierto placer hallado en la comodidad desmedida, una lasitud derivada más del amor excesivo a la vida y sus goces que de su rechazo. Es decir que el apego desmesurado al bien del cuerpo hace a estos enemigos reacios a los bienes del espíritu, cuya búsqueda muchas veces obliga a aplazar el placer inmediato difiriéndolo hacia un bien mayor. Un desvío de conducta menor para cualquier otro mortal, pero letal para un guerrero medieval que debe vivir en estado de alerta y actividad continuas, sacrificando el bienestar del cuerpo para beneficio del alma y gloria de Dios. Sin embargo, aunque estrictamente el desvío del que hablamos no coincide exactamente con el pecado de la acidia, debemos señalar que Peretó Rivas, en un estudio que traza la trayectoria del término acidia de la Patrística Oriental hasta el siglo XIV, advierte que éste pasa de ser una especie de

\footnotetext{
${ }^{7}$ Es decir que en el caso de la acidia estaríamos más ante una pereza espiritual que física, y esto más allá de que finalmente involucre la inacción del cuerpo, porque se caracteriza por un profundo estado de tristeza. De acuerdo a la definición de acidia que da santo Tomás en la Suma de Teología, se trata de: "una tristeza que de tal manera deprime el ánimo del hombre, que nada de lo que hace le agrada [...]. Por eso la acidia implica cierto hastío para obrar, [... incluso la tristeza que proviene de un mal real es mala en sus efectos cuando llega hasta el extremo de ser tan embarazosa que retrae totalmente al hombre de la obra buena" (Santo Tomás, Suma de Teología II, ii, 35.1, p. 318).
}

Medievalia 52:1, 2020, pp. 41-58 
"sequedad espiritual" a ser un desgano en relación con los deberes religiosos en la temprana Edad Media, para llegar al siglo XIV como un vicio contrario al espíritu de trabajo (Peretó Rivas, "El itinerario”, 37), caracterización que se acerca bastante al sentido que vamos a darle a la pereza en este estudio, como desorden contrario al esfuerzo y la constancia.

Con solo echar un vistazo al estudio de Romero, "Ideales y formas de vida señoriales", podemos advertir el choque entre cosmovisiones del que venimos hablando; el segundo subtítulo de su trabajo reza "La cortesía y el goce" y el tercero se denomina "La caballería y la misión", lo que da cuenta de ideales que se fueron contraponiendo y anulando a lo largo de la Edad Media. Estos ideales no tienen por qué haber sido excluyentes para los musulmanes, pero eso no importa al $P A O$, que presenta escenas que el poeta no reconstruye como un historiador objetivo, sino que recrea como escritor de la manera que necesita, de acuerdo con los fines que busca y, por ello mismo, de acuerdo con el principio épico de no contar la historia como fue, sino como debió haber sido. Es decir que el autor adjudica al adversario una actitud reprochable desde el punto de vista de los cristianos castellanos que, junto con otras razones, servirá para justificar su derrota y su exterminio.

De acuerdo con la dicotomía caballería vs cortesía o goce vs misión que plantea Romero, habría un comportamiento cortés propio de la aristocracia occidental, no reprochable en otro contexto, pero absolutamente inadecuado en tiempos de guerra, que es fácil de ejemplificar con la referencia a un conocido pasaje del Cantar de Mio Cid. En el episodio en que Rodrigo enfrenta al conde de Barcelona el atuendo que el poeta asigna a cada uno de los bandos anticipa el final de la contienda. ${ }^{8}$ La comodidad y la elegancia que caracterizan al bando de Berenguer Ramón II contrastan con las botas altas y el tipo de sillas que elige el Cid para su gente, pertrechados de modo tosco e incómodo, pero adecuado para el combate.

En el Poema de Alfonso Onceno, estas dos formas de encarar la vida son atribuidas incluso a los patronos de cada uno de los ejércitos de un modo tan rotundo que genera una sonrisa en el lector. Luego de las terribles pérdidas sufridas

\footnotetext{
8 "Ellos vienen cuesta yuso e todos traen calças,/ e las siellas coceras e las cinchas amojadas; / nos cavalgaremos siellas gallegas e huesas sobre calças” (vv. 992- 994. La cita corresponde a la edición del Cantar de Montaner). Cabe decir, de todos modos, que la cortesía es señalada, en este episodio, como inadecuación porque en este caso se esperaría una primacía de la misión, pero no hay en el Cantar un rechazo general de la cortesía sino que, como demostré en otro artículo, ambos ideales se exaltan en adecuación al contexto. El problema del conde es que intenta enfrentar una misión con una actitud cortés, esto es, sin adecuación al contexto.
} 
en el enfrentamiento con los cristianos, el rey Yusuf se lamenta, porque asegura haber visto al apóstol Santiago intervenir denodadamente en batalla en favor de los cristianos matando moros, desbaratando su compañía y quebrantando su seña (1887), ${ }^{9}$ mientras que la haraganería de Mahoma los dejó desprotegidos, sumando vergüenza a la derrota: "Santiago glorioso/ los moros fizo morir; / Mahomat, el perezoso,/ tardo, ${ }^{10}$ non quiso benir// e quando a Meca llegó/ echóse e adormeçió,/ o cuydo que se afogó/ con bruñuelos que comió” (1891-1892).

Esta explicación jocosa, pero humillante, que el poeta plenamente identificado con el vencedor cristiano pone en boca de Yusuf, connota en los calificativos que elige para cada una de las deidades uno de los mensajes más fuertes que el Poema intenta transmitir: la pereza es enemiga de la gloria. Un caso que ilustra esta idea es el del infante llamado Alí Caca, sobrino de Albohacén, a quien se describe como bravo y carnicero, dos atributos que se predican de Alfonso Onceno, y como extremadamente fuerte. Por ello, otro de los adjetivos aparentemente incongruente con semejante perfil que también lo califica, lleva a Victorio a corregir en su edición la lección que trae el manuscrito E. Dice el Ms. E sobre el infante, y así edita Ten Cate: "nunca vistes otro varón/ en lidiar más pereçoso” (v. 805d). Esta afirmación es leída por Victorio como un contrasentido en relación con la descripción anterior y por eso corrige en su edición "nunca vistes otro varón/ en lidiar más cobdiçioso" (Poema, 191, v. 806d). Pero si atendemos a la frase siguiente, en la que se continúa relatando el accionar del infante, veremos que tal contrasentido no existe, antes bien la afirmación conserva el tono de crítica a la pereza de los musulmanes que se va a mantener en el resto del Poema: "E ssu lança paresçe fuego/ quando con ella fería,/ e un freyre mató luego,/ non más en aquel día” (806). Teniendo las condiciones necesarias como para provocar un daño profundo en las filas enemigas se limita a enfrentar y dar muerte a un adversario que no está a su altura, no por cobardía, sino por pereza. Y esta actitud es la que justifica su inmediata muerte. Sabemos que puede ser esforzado si las circunstancias lo obligan a defender su vida ("real varón esforçado" v. 804c), y es por ello que para recibir muerte es acometido por "gran poder de cavalleros" (v. 807b), pero su destreza es defensiva antes que ofensiva y la despliega cuando no le queda más remedio que hacerlo o el lance es sumamente sencillo.

Lo acaecido con este infante no es más que una anticipación prefigurada del destino que le espera inmediatamente a Abomelique por una actitud

${ }^{9}$ Salvo que se indique otra cosa, cito por la edición del Poema de Ten Cate con número de estrofa y letra de verso si corresponde.

10 También podría editarse tardó.

Medievalia 52:1, 2020, pp. 41-58 
similar; y atendiendo a la sumatoria de casos, quizás debamos leer en estos ejemplos el final, y la justificación del final, con el triunfo de los cristianos. En tanto el texto da cuenta del avance implacable e ininterrumpido de los cristianos sobre el real, se dice de Abomelique "aún yazía en la cama/ el infante sandio e loco.// Coraçón de león fuerte/ e leno de grand porfia/ non cuydava en la muerte/ que açerca le venía” (vv. 790cd-791). Sus hombres le suplican que salga de la tienda, pero él minimiza los hechos asegurando que los cristianos solo están fanfarroneando. Su actitud, tan impropia de un guerrero, es acreedora de la muerte a manos de los esforzados cristianos que rechazan el descanso. Y el episodio deviene relato ejemplar, con moraleja incluida en boca del mismísimo Abomelique:

yo non oviera manziella/ si yo fuera arrancado/ de aquel rey de Castilla,/ que es un rey muy onrado.// Sus vasallos me mataron/ sin pres de cavallería:/ desarmado me fallaron/ en la cama en que yazía.// Si en cavallo estodiera/ en canpo con mi conpaña/ yo una paja non diera/ por quantos son en España (857-859).

$\mathrm{Al}$ igual que en la muerte precedente, que sirve de puesta en abismo de la de Abomelique y de refuerzo especular de la lección que debe recoger el lector, no se pone tampoco aquí en cuestión ni el valor ni las habilidades guerreras del hijo de Albohacén, pero la holgazanería augura resultados catastróficos para cualquier guerrero que no comprenda que el favor de Dios y el esfuerzo son las causas fundamentales de la victoria. Y habrá todavía una tercera escena construida de un modo similar, en la que vemos avanzar sin detenerse a los cristianos mientras al rey Albohacén se le sugiere descansar y dejar su delicada empresa en manos de otro:

[su alguacil] Dixo: 'Señor, si bos plaz/ en la buestra tienda folgade,/ dormide e avede paz/ non vos temades de nadi,// e señor, Dios lo confonda/ que ayades que temer/ en quanto la vuestra ronda/ yo tovier en mi poder.// Desto, señor, non vos miento,/ que ante querría ser muerto,/ los cristianos fueron çiento/ que pasaron por el puerto;// sus cuerpos aborreçieron/ en Tarifa son entrados./ Los moros plaser ovieron/ quando vieron estos mandados.// El rey se desarmava/ e todos a la ronda/ e al aguazil mandava/ que guardase bien la ronda (1494-1498).

El contraste que en el fragmento se introduce entre el descanso del rey moro, predispuesto a desarmarse, y la mención de los cristianos que "sus cuerpos aborreçieron" para entrar en Tarifa se refuerza unos pocos versos 
Erica Janin

después con la comparación implícita que emerge de la descripción que se hace de Alfonso XI, que oficia de paralelo y por contraposición genera una imagen laudatoria del rey castellano:

En la su tienda yazía/ non codiçiando tesoros,/ más deseando el día/ que se viese con los moros.// En la su cama yaziendo/ con saña del coraçón/ yazíase rebolviendo/ commo un bravo león// e a Dios Padre pedía/ que la mañana llegase; / e Dios le enbió el día/ e non quisso que tardase.// E el Seturno conplió/ su curso e amanesçió;/ el alva luego salió/ e la luz esclaresçió.// Alegró el coraçón/ quando el día llegó,/ a Dios fiso oraçión... (1500-1504).

En el momento obligado de descanso el rey castellano desea entrar en acción, más que cualquier otro tesoro, y ese deseo es el que le impide descansar, y le ruega a Dios que acelere la llegada del día, y su corazón se alegra con las primeras luces que preanuncian la batalla. El rey ora a Dios y le dice "por tu ley/ pongo el cuerpo en aventura" (vv. 1506cd), frase que duplica la enseñanza que el texto, como ya señalamos, busca transmitir: el favor de Dios y el esfuerzo conducen a la gloria. Albohacén intenta huir para evitar la muerte, y no teme la deshonra, sino que su temor más grande es no volver a ver a su mujer:

'Tomemos del mal el poco,/ oy nos vino cuyta fuerte;/ non tienen omne por loco/ si puede fuir de muerte.// Del mal tomemos el menos/ e lo ál vaya su vía./ De la muerte escapemos,/ iguaresçer, cavallería!// Rey mesquino, ¿qué faré?/ ¡Oy me vino muy mal día!/ Ya vos nunca veré,/ ¡oy!, Fátima la tuniçía’ (1710-1712).

Lo que paradójicamente terminará enseñando el Poema es que quien más expone su cuerpo más lo preserva, pues el que descansa, muere. ${ }^{11}$ No por

\footnotetext{
${ }^{11}$ Podemos reforzar esta idea con otra cita: "Estamos en la estrechura/ en las prayas deste mar/ e llégasse la friura/ non podemos aquí morar.// Viandas aquí non están/ e si más quisieremos yazer/ aína fallesçerán,/ non ternemos que comer.// A los moros non tardemos,/ manaña en aquel día/ en la batalla entremos,/ cunplamos nuestra romería" (1446-1448). El pasaje deja en claro que no hay tiempo para yacer cuando falta el alimento y los enemigos acechan. La guerra vuelve al guerrero enemigo del descanso y este desasosiego de Alfonso cuando no le queda más remedio que aguardar en la cama no es nada casual, sino un modo del poeta de mostrar la intensidad con la que debe rechazarse la inacción del guerrero en tiempos de enfrentamientos bélicos. $\mathrm{Al}$ respecto cabe recordar también un pasaje anterior del mismo tono: "En la su cama yaziendo/ començó mucho a penssar,/ yazíasse rebolviendo/ que non podía folgar" (1234). Cuando al rey no le queda más remedio que estar en la cama, lo hace a
}

Medievalia 52:1, 2020, pp. 41-58 
casualidad en la alegoría animalística que profetiza la alianza y el triunfo de los reyes de Castilla y Portugal sobre los benimerines, Alfonso IV, que aún se muestra indeciso en cuanto a su participación en la causa cristiana en apoyo del rey de Castilla, es representado como un león durmiente al que el león coronado, Alfonso XI, despierta de su letargo para sumarlo a su causa armada contra los enemigos de la fe (1808-1843). El camino del esfuerzo y el sacrificio es una elección. ${ }^{12} \mathrm{Y}$ es una elección por amor a Dios. ${ }^{13}$

Estas diferencias entre cristianos y moros se ven incluso en situaciones de deliberación, en momentos en que no están en el campo de batalla. Mientras que en las escenas que se desarrollan en el estrado de Alfonso se observa una insistencia en caracterizar el espacio como un ámbito de discusión de cuestiones serias marcado por cierta tensión, pues allí también llegan mensajeros con noticias de primera importancia; en el caso de los moros vemos una actitud muy distinta entre el rey y sus consejeros, mucho más vinculada a la comodidad: "Un moro allí seía/ grand alfaje de la ley,/ acostado yazía/ en el estrado del rey" (1366) y más adelante "Guisáronse aquel día/ amos a dos en el estrado/ e don Ascar í yazía/ cabo del rey acostado” (2363).

Pero lo interesante es que hay algo que va más allá de la consideración general de ser cristiano y esforzado, en clara oposición al moro perezoso, y es que la realización más perfecta del esfuerzo concreta su potencialidad en los guerreros castellanos que apoyan al rey, cuyos desempeños pueden compararse con los de sus pares europeos en las situaciones límite a las que lleva la guerra, ya que, como es sabido, la empresa de Alfonso XI, al igual que las cruzadas, contó con la presencia de cristianos de otras latitudes que deseaban colaborar en las campañas contra el infiel. Cuando la situación, durante el cerco de Algeciras, se vuelve realmente riesgosa y la guerra comienza a mostrar su cara más brutal sumando a la enorme cantidad de caídos en batalla, la pérdida de caballos, el hambre, el frío, la enfermedad, "Los estraños se tornaron/ cada unos para sus tierras;/ los castellanos fueron [o fincaron, como sugería Catalán]/ que saben sofrir las guerras" (2293). En situaciones extremas otros guerreros del resto de Europa flaquean, no por pereza como hemos visto que ocurre a

disgusto, y cambia la actividad física por actividad mental de manera de desperdiciar la menor cantidad de tiempo posible. El tiempo en que el cuerpo reposa es utilizado para diseñar estrategias, de modo que la imagen real que se proyecta es la de un rey guerrero que vela en tiempos de guerra por el bien de sus vasallos y de la cristiandad.

12 "E mucha lazería toma/ por honrar la cristiandat" (vv. 1912ab), "Commo señor acuçioso/ non lo puso en vagar" (vv. 2081ab), "por llegar contra la mar/grand afán quiso sofrir” (vv. 2084ab).

13 "Desanparé las mis tierras,/ que yo podiera folgar,/ con los moros tomé guerras/ por tu fe acreçentar" (2301). 
veces entre los musulmanes, sino por la exposición a condiciones muy adversas incluso para nobles duchos en el oficio bélico. Es la doble condición de cristianos y castellanos la dadora de esta fortaleza tan singular que encarna principalmente en el rey Alfonso XI, que se vuelve un espejo para sus hombres.

Para Romero, la Iglesia, que no siempre había logrado imponer sus principios morales, lucha para poner límites a los hábitos tradicionales de la aristocracia tratando de incidir en su sistema de valores y relaciones, oponiendo sus propios principios. Y el ideal de goce inherente a esta clase se advertía como anticristiano ("Ideales y formas", 1). A lo que hay que sumar el empeño en varios textos bajomedievales por dejar en claro que la ocupación de la nobleza es la guerra y que, como bien señala Guglielmi, directamente "algunos testimonios consideran la guerra de conquista como un trabajo" ("La cultura”, 141). Es decir que, en alguna medida, y como objetivo complementario de la justificación de la derrota y el exterminio de los enemigos, también el Poema puede estar dando cuenta de una lucha de valores que se da internamente en el campo cristiano, pero objetivándola en el campo musulmán, al exponer frente al receptor del Poema que las conductas ociosas son propias de infieles, y son reprochables en un guerrero cristiano. La "misión", a la vez terrena y trascendente, sublima el esfuerzo como valor en la caballería.

Podemos ir más lejos y pensar que lo que se propone como ideal de vida general, con el esfuerzo como uno de sus ejes rectores y el ocio como antivalor, se ancla en el Poema en ejemplos y contraejemplos bien concretos que permiten derivar de la lectura moral, cristiana o caballeresca, una lectura política. Un acercamiento focalizado en los diferentes grupos que interactúan en la obra nos deja ver que la conducta esforzada que se promueve se concreta en la caballería de la Orden de la Banda, varias veces invocada, y también se muestra como una característica propia de la nueva nobleza andaluza que Alfonso XI está promoviendo en estos años de enfrentamiento con los musulmanes.

Luego de señalar las operaciones de sentido que se montan sobre el accionar de los enemigos, es necesario comentar, aunque sea brevemente, cómo se proyecta positivamente el ideal del esfuerzo sobre los grupos que el Poema busca destacar. En el caso de la Orden de la Banda, varias son las veces en que se la caracteriza como un conjunto de hombres esforzados. Basta recordar un ejemplo:

Vuestras almas salvaredes,/ moros avrán rancura;/ del vuestro rey saberedes/ cómmo el cuerpo aventura.// En esta lid entraré/ commo sienpre fablaran;/ los de la Vanda veré/ cómmo me aguardarán// e cómmo serán esforçados/ en faser golpes çerteros,/ e los donçeles mis criados/ver querré si son braçeros.// 
Pensemos de prez ganar/ todos por cavallería,/ que sienpre ayan que fablar/ de mañana aquel día.// Si esta lid yo vençier/ a vos grand loor darán,/ naçidos e por naçer/ ya por sienpre fablarán,// e si nos fuéremos vençidos/ será grand tribulaçión:/ los cristianos son perdidos/ de mar a mar quantos son (14351440).

Como se ve en esta cita, la envergadura de la empresa hace imprescindible y, a la vez, ineludible el esfuerzo, porque una derrota a manos de los moros implicaría una pérdida irreparable para la cristiandad. Del esfuerzo de todos y de cada uno de estos guerreros depende la hegemonía cristiana. Como bien ha señalado Rodríguez-Velasco, Alfonso XI busca, más que ningún otro rey castellano, reordenar su relación con la nobleza a través de la caballería ( $\mathrm{Ciu}$ dadanía, 51), ya que por medio de ella controla la estructura social de la clase caballeresca. Esta posibilidad de cambio social de la nobleza que Alfonso promueve a través de la caballería, no sólo es advertida sino también padecida por la vieja nobleza, especialmente por don Juan Manuel (67), que ve mermar su poder frente a este nuevo grupo que sostenía al rey, al tiempo que le permitía ocupar el territorio (143). Y en este sentido, la arenga de Alfonso a sus hombres al llegar al Salado (estrofas 1558 a 1573) es un ejemplo perfecto para estudiar el impacto de las aspiraciones políticas e ideológicas en la literatura, dado que en ese pasaje central del texto se recogen todas las líneas de sentido que el poeta tendió a lo largo de su obra: la figura del rey guerrero, el modelo del esfuerzo (al que se apela con insistencia en ese pasaje) como virtud transversal que atañe tanto al rey como al más raso de los soldados, el anhelo de integrar al proyecto a todos los estamentos de la nobleza ("cavalleros e peones"), la relevancia de la Orden de la Banda y la política de mercedes, libramientos y quitaciones como sostén del proyecto expansionista y de fortalecimiento de la autoridad regia. ${ }^{14}$

14 "Al Salado fue llegando/ este rey noble varón/ e los moros oteando/ commo un bravo león// dixo: 'Amigos, esforçar,/ la mi linpia criazón,/ agora viesse en este logar/ quantos en el mundo son.// Cavalleros e peones,/ el día es muy alçado;/ vayamos tomar quitaçiones/ allende el río del Salado.// Ya el día mucho anda./ ¡Esforçar, cristiandat!/ ¡Cavalleros de la Vanda,/ oy beré buestra bondat!// ¡Esforçar e non temer cosa/ al ferir de la espada;/ que la Vanda muy fermosa/ oy sea por bos honrada!// Esto es cavallería/ e yo a vos mientes terné;/ guardemos para este día/ que yo mucho deseé.// Nos luego faremos/ a poder de escudo e lança;/ la sangre derramaremos/ por medio de la matança.// Las lanças non echaremos,/ mas ferir a manteniente,/ golpes çerteros faremos/feridos espessamiente.// E si la lança quebrar/ de los golpes que fezieren/ sépanse bien ayudar/ de las espadas que tovieren.// Oy beré quién me ayuda,/ e si la lid bençier/ con razón buena, tenuda/ gelo cuydo cognosçer.// Fazerle he 
Algo similar ocurre con varios de los miembros de la nobleza andaluza, que son los que en ocasiones toman en el Poema los principales riesgos en los enfrentamientos contra los moros, y juegan en tándem con los caballeros de la Banda. Mientras los caballeros de la Orden tienen, salvo alguna excepción, una misión grupal de acompañamiento y protección del rey, la nobleza andaluza y otros nobles del entorno íntimo, son los que cuentan con el privilegio de ser nombrados, y por lo tanto destacados, individualmente como premio por su arrojo y para subrayar que se trata de una capa más elevada de la nobleza muy cercana al rey y reconocida personalmente por éste, que está tomando el lugar que en tiempos pretéritos tuvieron don Juan Manuel y sus aliados, e incluso otros nobles anteriormente encumbrados por el mismo Alfonso, como el maestre de Alcántara, Martínez de Oviedo, que había caído en desgracia. Entre los nobles leales individualizados se puede mencionar, entre otros, a Alonso Fernández Coronel, uno de sus principales privados, nombrado varias veces en el Poema y también miembro de la Banda, ${ }^{15}$ Juan Alfonso de Benavides, Juan Rodríguez Sandoval, Martín Fernández de Portocarrero, Enrique Enríquez y, por supuesto, varios “del linaje de Guzmán” (v. 709b), entre quienes cabe destacar a Alonso Méndez de Guzmán, hermano de doña Leonor, nombrado maestre de la Orden de Santiago en 1338, que muere en batalla protegiendo al rey y a sus hombres, y se convierte así en un ejemplo a imitar.

Como destaca Arias Guillén, fueron de enorme importancia las redes personales que el monarca tejió en torno a sí porque de ese modo pudo ubicar a personajes de su confianza en lugares clave, como los maestrazgos de las órdenes militares. Y así adquirió primera importancia Leonor de Guzmán.

merçed conplida/ commo biva sin porfaço,/ llamarlo he en mi vida/ mi escudo e mi braço.// En el mi cuento granado/ yo lo cuido deponer/ que sienpre sea nonbrado/ el buen fecho que fezier.// Por aquesto esforçedes/ en fazer golpes çerteros/ e los moros non dubdedes/ más que si fuesen corderos.// ¡Non ayades que temer/ estos moros que son pocos;/ convusco cuydo vençer/ este dragón de Marruecos!// E aquesta será su fin,/ Dios nos querrá ayudar,/ que el rey de Benamarín/ nos non podrá escapar.// E perderá su alteza,/ su esfuerço e su gente/ e África su nobleza/ con los poderes de Oriente"” (1558-1573). También podemos citar el siguiente ejemplo: "Luego la frota fue guisada/ con ricos omnes honrados,/ fijos dalgo de la mesnada/ ligeros e esforçados,// caballeros de la Vanda;/ el rey les dio conplimiento' asáz de mucha vianda/ e fízoles libramiento" (2365-2366). Para el tema del fortalecimiento de la autoridad, el expansionismo y la política impositiva y de mercedes pueden consultarse tanto Arias Guillén (Guerra y fortalecimiento, cap. 5) como González Mínguez (Poder real, caps. 12, 13 y 14$)$.

${ }^{15}$ Ver Fernández de Córdova Millares (“El emblema”, 127) y Segura González ("La derrota", 14). 
La relación con la dama andaluza le facilitó la integración de la nobleza de esa zona en la esfera real, lo que fue trascendental en el aspecto bélico, pues junto con los concejos de Frontera constituyeron la base de las huestes reales. Y los hijos que tuvo con ella le permitieron crear séquitos y casas en los que situar a diversos personajes de la Corte, premiando su servicio y fortaleciendo su relación con la Corona (Arias Guillén, Guerra y fortalecimiento, 162). ${ }^{16}$

Son los nobles leales de la Corte, los caballeros de la Banda y la nobleza andaluza el modelo de esfuerzo que propone el Poema, cuyo paradigma es el mismísimo Alfonso XI. Esta insistencia en la pereza y en su contracara, el esfuerzo, opera, como hemos visto, en varios sentidos al mismo tiempo. Justifica el ascenso de estos nuevos nobles al dar cuenta de su relevancia en la batalla, refuerza la identidad cristiana separando fieles de infieles y oficia de llamado de atención claro para los nobles que eventualmente puedan rehusarse a pelear, al tiempo que señala a los rebeldes que incurrieron en tales inconductas y sirve para justificar las medidas que el rey pudo haber tomado en su contra.

Parece bastante evidente, como ha sugerido Deyermond, que el PAO busca también responder las acusaciones que don Juan Manuel dejara asentadas en el Libro de las tres razones contra el rey. ${ }^{17}$ Suponemos que el Libro de las tres razones, además de transmitir otra perspectiva de los hechos, puede estar

${ }^{16}$ Arias Guillén examina detalladamente este tema en un artículo de 2015, cuya hipótesis central plantea que si bien anteriormente el rey ya se había servido, en los casos de Constanza Manuel y de María de Portugal, de la política matrimonial para consolidar su poder, su relación con Leonor resultará crucial para convertirse en el lider de una poderosa facción de la nobleza constituida por familiares de ella. Esto favoreció la imposición del poder de Alfonso sobre los nobles opositores, pero también la negociación de la incorporación de estos al bando real ("Family Matters", 295). Aunque fuera común que los reyes tuvieran relaciones extramatrimoniales, la novedad del caso de Alfonso radicó no sólo en la estabilidad, sino también en la duración de ese vínculo con la dama andaluza, lo que colaboró con la expansión de la autoridad real ("Family Matters", 302).

${ }^{17}$ Alan Deyermond, en un artículo dedicado a la cronística de Alfonso XI, esboza la idea de que el Poema tal vez sea una respuesta al Libro de las tres razones, pero no la desarrolla ni la justifica (Deyermond, "Written”. Ver especialmente pp. 59-65). Creo que el postulado es acertado y que toma más cuerpo cuando cada una de las obras literarias e historiográficas a las que fui haciendo referencia se piensa como integrante de un sistema de producciones en disputa que proyectan determinadas imágenes del nosotros y de los otros. De modo que, como advierte Aurell, el medievalista más que aspirar a estudiar los hechos que narran estas obras debería interesarse por estudiar la codificacción de esos hechos (Aurell, "El nuevo”, 813). En este sentido, el Poema contesta construyendo un relato mediante el cual la sola exposición de los hechos y dichos de don Juan Manuel, recortados y ordenados del modo conveniente, deja claro que ni fue tan leal ni tan confiable ni estuvo dispuesto a sacrificar su vida por el rey, como él afirmaba. 
respondiendo, a su vez, a las acusaciones de traición contra don Juan Manuel que se aventuran en la Crónica de Alfonso Onceno, donde se señala su inacción o falta de esfuerzo en la batalla del Salado como un daño gravísimo; aunque unas décadas después esas acusaciones se morigeran en la Gran Crónica de Alfonso Onceno cuando las necesidades políticas delinean otro perfil de don Juan Manuel, rediseñado en las interpolaciones a fuerza de explicaciones de su accionar que redireccionan la interpretación del lector de modo de limpiar al magnate del delito de traición por el abandono de sus obligaciones. ${ }^{18}$

En síntesis, es a través de la promoción del ideal del esfuerzo como algo propio de la nobleza que acompaña al rey, desde sus capas inferiores hasta la más encumbrada, que el Poema hilvana las secuencias del relato en dos hilos, pues no sólo cuenta cómo Alfonso vence a los musulmanes, sino también cómo vence a la nobleza rebelde que, una vez controlada, terminará peleando codo a codo y bajo las órdenes de esta otra nobleza elegida y distinguida por el rey. ${ }^{19}$ En este sentido el relato deja claro que el objetivo de Alfonso XI siempre fue aglutinar bajo sus órdenes todas las capas de la nobleza para conducirla a la lucha contra el Islam. ${ }^{20}$

El Poema legitima y celebra, de esta manera, a todos los personajes promovidos por Alfonso por haber aventurado su cuerpo por la causa de Dios, del rey y del reino; y delimita el campo del bien y del mal, unificando enemigos internos y externos como perezosos que rehúyen el enfrentamiento si este no asegura un inmediato beneficio personal.

\footnotetext{
${ }^{18}$ Puede verse al respecto el artículo de Orduna, "El Libro de las Armas". Allí da cuenta de que en la Crónica no se mencionan los verdaderos motivos por los que don Juan Manuel se desnatura en 1327 del rey (p. 240) y también de que Crónica y Gran Crónica difieren en el relato de la embajada del rey de Portugal para instar a Alfonso XI a que levantara el cerco de Lerma (p. 242). Y aporta un fino análisis del diferente relato que de la intervención de don Juan en la batalla del Salado hacen Crónica y Gran Crónica, al tiempo que intenta explicar cuáles pudieron haber sido los verdaderos motivos por los que el magnate no interviene en la batalla de manera decidida (ver pp. 250 a 254).

${ }^{19}$ Después de su pedido de perdón al rey por haberse desentendido de sus obligaciones mirando más por su estado que por el bien de la cristiandad (ver estrofas 1283-1285), don Juan Manuel terminará poniendo a sus hombres y a sí mismo al servicio del maestre de Santiago: “...el maestre de Santiago/ allí mostró grand bondat,// don Alfonso Méndez de Guzmán,/ onrado varón fiel,/ con la delantera de don Johan,/ fijo del infante don Manuel// e don Johan Núñez de Lara/ feriendo de coraçon...” (1727 cd-1729ab).

20 Para este tema ver Rojas Gabriel, "El triunfo" (en especial p. 628).
} 


\section{BiBLIOGRAFÍA}

Arias Guillén, Fernando, Guerra y fortalecimiento del poder regio en Castilla. El reinado de Alfonso XI (1312-1350), Madrid: Ministerio de Defensa/ Consejo Superior de Investigaciones Científicas, 2012.

Arias Guillén, Fernando, "Family Matters: Marriage Strategy and the Strengthening of Royal Authority in Castile During the Reign of Alfonso XI (13121350)", Viator, 47:1, 2015, 293-312.

Aurell, Jaume, "El nuevo medievalismo y la interpretación de los textos históricos”, HISPANIA. Revista Española de Historia, LXVI:224, (septiembre-diciembre) 2006, 809-832.

Cantar de Mio Cid, ed. de Alberto Montaner, Madrid: Real Academia Española-Barcelona: Galaxia Gutenberg-Círculo de Lectores, 2012.

Cantar de Roldán, ed. y trad. de Isabel de Riquer, Madrid: Gredos, 1999.

Catalán Menéndez-Pidal, Diego, Poema de Alfonso XI: fuentes, dialecto, estilo, Madrid: Gredos, 1953.

Cela Heffel, Emilio, "La función de la cosmovisión del moro en el Poema de Alfonso Onceno", en Gloria Chicote y Lía Galán (eds.), Diálogos Culturales. Actas VII Jornadas de Estudios Clásicos y Medievales, 7 al 9 de octubre de 2015, Ensenada: Universidad Nacional de La Plata-Facultad de Humanidades y Ciencias de la Educación-Centro de Estudios Latinos, 2016 [disponible en: http://www. memoria.fahce.unlp.edu.ar/trab_eventos/ev.7547/ev.7547.pdf]

Corbalán VÉlez, ANA, "Aproximación a la imagen del musulmán en la España medieval", Lemir, 7, 2003, 1-27.

Deyermond, Alan, "Written by the Victors: Technique and Ideology in Official Historiography in Verse in Late-Medieval Spain”, en Erik Kooper (ed.), The Medieval Chronicle, VI, Amsterdam-New York: Rodopi, 2009, 59-90.

Don Juan Manuel, "Libro de las tres razones”, en Reinaldo Ayerbe-Chaux (ed.), Cinco Tratados, Madison: The Hispanic Seminary of Medieval Studies, 1989, 91-112.

Fernández de Córdova Millares, Álvaro, "El emblema de La Banda entre la identidad dinástica y la pugna política en la Castilla bajomedieval”, Emblemata, 20-21, 2014-2015, 121-170.

Fernández Gallardo, Luis, "Guerra santa y cruzada en el ciclo cronístico de Alfonso XI”, En la España Medieval, 33, 2010, 43-74.

García SanjuÁn, Alejandro, "Alfonso XI frente a los musulmanes en las fuentes árabes”, en Manuel García Fernández (coord.), El siglo XIV en primera persona. Alfonso XI, Rey de Castilla y León (1312-1350), Sevilla: Universidad de Sevilla, 2015, 53-70. 
Erica Janin

Gómez Redondo, Fernando, Historia de la métrica medieval castellana, Madrid: Cilengua-Fundación San Millán de la Cogolla, 2016.

González Mínguez, César, Poder real y poder nobiliar en la Corona de Castilla (1252-1369), Bilbao: Universidad del País Vasco/ Euskal Herriko Unibertsitatea, Argitalpen Zerbitzua = Servicio editorial, 2012.

Gran Crónica de Alfonso XI, ed. de Diego Catalán, Madrid: Gredos, 1977.

Guglielmi, Nilda, "La cultura del Ocio", Acta Historica et Archaeologica Mediaevalia, $18,1997,135-153$.

Janin, Erica, "Una vez más sobre el género del Poema de Alfonso Onceno: ¿historiografía en verso o épica?", Estudios de Historia de España, XXI:1, 2019, 1-25 [http://erevistas.uca.edu.ar/index.php/EHE/article/view/2096/1946].

Nogales Rincón, David, "Animalización, sátira y propaganda real: la metáfora y la alegoría animal como instrumento político en la Castilla bajomedieval (siglos XIV-Xv)”, Revista Signum, 11:1, 2010, 267- 296.

Nussbaum, María Fernanda, Claves del entorno ideológico del Poema de Alfonso XI, Lausanne: Sociedad Suiza de Estudios Hispánicos, 2012.

Orduna, German, “El Libro de las Armas: clave de la 'justicia' de don Juan Manuel”, Cuadernos de Historia de España, LXVII-LXVIII, 1982, 230-268.

Peretó Rivas, Rubén, "El itinerario medieval de la acedia”, Intus-Legere Historia, 4:1, 2010, 33-48.

Poema de Alfonso XI, ed. de Yo Ten Cate, Anejo LXV de la Revista de Filología Española, Madrid: Consejo Superior de Investigaciones Científicas, 1956.

Poema de Alfonso Onceno, ed. de Juan Victorio, Madrid: Cátedra, 1991.

Rodríguez- Picavea, Enrique, "La visión del Otro: la imagen del musulmán en el Poema de Alfonso XI", en Carlos de Ayala Martínez e Isabel Fernandes (coords.), Cristãos contra muçulmanos na idade média peninsular: bases ideológicas e doutrinais de um confronto (séculos X-XIV), Lisboa: Edições Colibri-Universidad Autónoma de Madrid, 2015, 369-396.

Rodríguez-Velasco, Jesús, Ciudadanía, soberanía monárquica y caballería. Poética del orden de caballería, Madrid: AKAL, 2009.

Rojas GABRIEL, MANuEL, "El triunfo de las monarquías”, en Vicente Álvarez Palenzuela (coord.), Historia de España de la Edad Media, Barcelona: Ariel, 2011, 627- 644.

Romero, José Luis, "Ideales y formas de vida señoriales en la alta Edad Media”, http://jlromero.com.ar/publicaciones/ideales-y-formas-de-vida-senorialesen-la-alta-edad-media-1959 [Publicado originalmente en Revista de la Universidad de Buenos Aires, 4:2, abril-junio 1959, 175-178].

Santo Tomás de Aquino, Suma de Teología, ed., de los Regentes de Estudios de las Provincias Dominicanas en España, estudio preliminar de Damian Byrne, Madrid: Biblioteca de Autores Cristianos, 2001.

Medievalia 52:1, 2020, pp. 41-58 
Segura González, Wenceslao, "La derrota naval del Almirante Jofre Tenorio", Aljaranda, 70, 2008, 9-14.

Vaquero, Mercedes, El "Poema de Alfonso XI": ¿crónica rimada o épica?, Michigan: University of Michigan, 1984.

Vaquero, Mercedes, “Contexto literario de las crónicas rimadas medievales", Dispositio, X:27, 1985, 45-63. 